\title{
X-ray diffraction characterization of ion-implanted austenitic stainless steel
}

\author{
M.J. Marques ${ }^{\mathrm{a}, *}$ J. Pina $^{\mathrm{b}}$, A.M. Dias ${ }^{\mathrm{b}}$, J.L. Lebrun ${ }^{\mathrm{c}}$, J. Feugeas ${ }^{\mathrm{d}}$ \\ ${ }^{a}$ Universidade Católica Portuguesa, Pólo da Figueira da Foz, Rua Dr. Mendes Pinheiro, no. 24, P-3080-032 Figueira da Foz, Portugal \\ ${ }^{\mathrm{b}}$ GTR, Departamento de Física, Universidade de Coimbra, P-3004-516, Coimbra, Portugal \\ ${ }^{\mathrm{c}}$ LPMI-ERTGI, ENSAM, 2 Bd. Du Ronceray, 49000 Angers, France \\ ${ }^{\mathrm{d}}$ Instituto de Física Rosario (CONICET-Universidad Nacional de Rosario). Bv. 27 de Febrero 210 Bis., 2000 Rosario, Argentine
}

Received 8 August 2003; accepted in revised form 4 June 2004

\begin{abstract}
The effect of ion implantation surface treatment in an austenitic stainless steel, AISI 304, with nitrogen and argon ions is presented in this work. The study concerns phase analysis, crystallographic texture, and in depth residual stress profile characterization by X-ray diffraction. In order to determine the residual stress depth profiles, a combination of the conventional X-ray diffraction technique, with several wavelengths radiation, and the pseudograzing incidence X-ray diffraction are used. Experimental data leads to the conclusion that the ion implantation did not create any new phase and did not influence the crystallographic texture observed before the implantation. However, concerning the residual stresses study, the results show that the initial compression residual stress profile observed in the nonimplanted surface samples changes to a tensile residual stress profile after implantation. A very important residual stress gradient is induced in the implanted surfaces and becomes more significant with the increase of ion beam fluence. In this surface layer, the tensile residual stress average value increases with the total fluence of ion beam. Ar ions seem to increase the residual stress profile more than $\mathrm{N}$ ions. The diffraction peak width evolution with depth is similar in nonimplanted and in implanted zones for both types of implanted ions. The peak width is much larger in the first micron of the surface layer, decreasing at a greater depth, reaching the corresponding peak value of the recrystallized material (6000-7000 $\mathrm{nm})$.
\end{abstract}

(C) 2004 Elsevier B.V. All rights reserved.

Keywords: $[\mathrm{C}]$ Ion implantation; $[\mathrm{X}]$ Grazing incidence X-ray diffraction

\section{Introduction}

During the last years, the materials demand gave rise to an important improvement in the techniques to modify surfaces. Ion implantation is one of these techniques, which has been studied and applied in several areas. This method induces modifications in the physical and chemical properties at surface layers. Ion implantation has the advantage to create a progressive interface between the implanted surface layer and the volume of unaffected material without modifying the original dimensions of the material. The

\footnotetext{
* Corresponding author. Tel.: +351 233428445; fax: +351 233428847.

E-mail addresses: mjm@crb.ucp.pt (M.J. Marques), lebrun@angers.ensam.fr (J.L. Lebrun).
}

ion implantation does not present, consequently, the adherence problems very common to other surface treatments, such as deposition of thin films. The basic problem of ion implantation is the selection of the duplex matrix/ deposit and ion implantation conditions in order to obtain the desirable properties in the matrix surface. One of the main application fields of ion implantation is the improvement of tribological properties of materials [1-3]. Usually, the ion implantation decreases the abrasive wear coefficient of implanted surfaces. Another application is the amelioration of corrosion resistance. An extensive bibliographic review about the influence of ion implantation in the aqueous resistance of the iron and steel corrosion is presented in the publication [4].

The ion implantation process induces microstructural changes, which could give the origin of residual stress in the 
treated materials. Residual stresses have a strong influence in the final tribological and mechanical properties of materials, particularly steels. Among a large variety of processes oriented to the surface modification exclusively, fast thermal treatment and ion implantation are two of them used with different purposes. The first one, mainly based in the use of high-power lasers, is used for cutting and welding, localized surface hardening, and alloying, etc. The second one, based in the use of high-energy particle accelerators, is currently used in surface modification through the inclusion of atomic species, developing specific compounds, modifying the previously existing crystal structure, etc., covering depths normally lower than $1 \mu \mathrm{m}$. As a result, the surface properties are also strongly modified. As a new alternative, experiments of surface modifications with pulsed ion beam were done using coaxial plasma guns operated in the detonation mode as acceleration mechanism. In this case, two basic differences concerning traditional ion implantation processes can be remarked: one is the polyenergetic characteristic of the beam, and the other is the combination of the high-flux and short-beam duration. The first difference gives rise to a continuous concentration profile under the surface, without abrupt variations, opposite to the monoenergetic ion beam case. The second difference creates a strong thermal effect developed due to the fast energy relieve in the surface layers, not allowing a thermal surface relaxation through the more slower mechanism of thermal conduction to the bulk of the target. As a result, the surface treatment with the pulsed ion beam can be associated to a virtual combined effect of pure ion implantation process and a strong thermal shock.

This paper has the objective to study the modifications introduced by nitrogen $(\mathrm{N})$ and argon (Ar) ions, implanted with a plasma coaxial torch, in AISI 304 austenitic stainless steel. Several samples were implanted with different fluency for both types of ions. The effect of a nonreactive ion, like Ar, compared with a reactive one $(\mathrm{N})$ could influence the surface modified layer. The study presents the characterization of crystallographic phases, texture, and depth profiles of residual stresses determined by X-ray diffraction (XRD). The residual stress evaluation at different depths was obtained using the conventional "' $\sin ^{2} \psi$ method using $\mathrm{Mn}, \mathrm{Cr}$, and $\mathrm{Cu} \mathrm{K} \alpha$ radiations and using the pseudograzing incidence X-ray diffraction method (PGIXRD) with $\mathrm{Cu} \mathrm{K \alpha}$ radiation. The X-ray acquisitions were made in the rolling and transverse directions $\left(\phi=0^{\circ}\right.$ and $\phi=90^{\circ}$, respectively). The study was performed in the implanted zones and in the nonimplanted zones, in order to understand the effect of the ion implantation.

\subsection{Short description about the ion implantation with a plasma coaxial torch}

Plasma Focus (PF) is a coaxial plasma gun operated in a detonation mode. In Fig. 1, a diagram with a longitudinal cut of the coaxial electrode system is presented with a

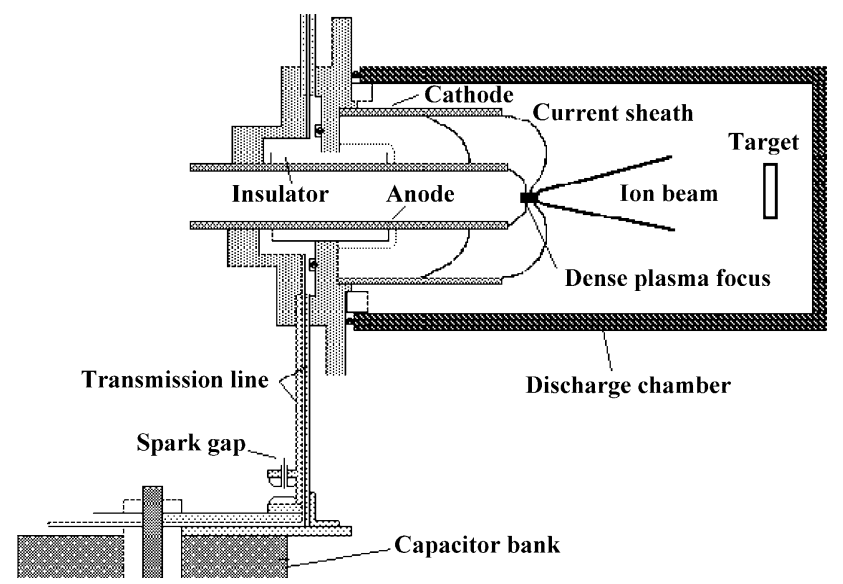

Fig. 1. Diagram of the experiment of pulsed ion implantation.

discharge stage scheme. The PF used in our experiments had a geometry, which corresponds to a Mather type [5], characterized by the condition in which the gun electrodes length $L$ is approximately equal to the outer gun diameter $\phi$ $(L \sim \phi)$, differentiated with respect to the Filipov geometry for which $\phi \gg L$. The system used in our experiments has an $L=70 \mathrm{~mm}$ and a $\phi=70 \mathrm{~mm}$.

With the help of Fig. 1, the operation of the PF can briefly be described as follows [5,6]: the system consists of two coaxial cylinders built in brass, open at one end, but one insulated with respect to the other by a coaxial Pyrex pipe. The volume between the electrodes is filled with a pure gas at low pressure (200 mTorr), being the gas of the same nature than the ion specie to be accelerated. The electrodes are connected to a capacitor bank through a low-impedance transmission line, interrupted only by a fast switch (sparkgap type). The central electrode is connected to the positive (anode) and the outer electrode to the negative voltage (cathode).

The energy storage in the capacitor bank $(1 \mathrm{~kJ}$ at $20 \mathrm{kV}$ charging voltage, in our case) is discharged into the coaxial electrode system through a transmission line by triggering the spark-gap switch. If the design (geometrical and physical parameters) is optimized, the discharge begins (breakdown) as a gliding discharge on the Pyrex pipe insulator surface at close extreme of the gun. The interaction between the current carried in the current sheath with the self-generated magnetic field blows the current sheath to the open end. Once at the end, the current sheath collapses developing a high-density plasma column or dense plasma focus (DPF) in front of the anode and along the axis of symmetry of the gun. In our experiment, the DPF column has $\sim 7 \mathrm{~mm}$ of length and $\sim 1 \mathrm{~mm}$ of diameter, and the whole process lasts (time between the breakdown and the collapse) 850 ns. During the DPF formation, the electric current reaches the maximum (which in our case is $200 \mathrm{kA}$ ), leading to place Rayleigh Taylor instabilities and ion and electron beam acceleration as shown in Fig. 1. These processes are accompanied with bursts of X-rays. 
The ion beam is accelerated in the $0^{\circ}$ direction (see Fig. 1) with an energy distribution, which follows a spectral law $[7,8]$ expressed as

$\mathrm{d} N / \mathrm{d} E \sim E^{-3.4}$

where $N$ is the number of ions with energy $E$, with an $E$ minimum value of $\sim 20 \mathrm{keV}$ and an observed maximum of several megaelectron volts. While the minimum can be associated to the operation voltage of the PF (which in our case is $20 \mathrm{kV}$ ) or to the peak voltage reached between the electrodes at the moment of DPF formation, the maximum is intrinsically associated to the acceleration process in the PF during the Rayleigh Taylor instabilities development.

The experiments of ion implantation were done by the exposure of targets to the beam at a distance $l=80 \mathrm{~mm}$ down stream from the DPF column, giving a fluence per shot $f=1.3 \times 10^{14}$ ions $/ \mathrm{cm}^{2}$. To obtain higher fluences, the target was exposed to a successive predetermined number $n$ of single ion beam pulses, resulting in an accumulated total fluence $F=n f$.

\subsection{Pseudograzing incidence method}

The $\sin ^{2} \psi$ method to determine residual stress by XRD has been fully described in 1961 [9]. Since then, several publications have been written in order to develop or to apply the method to material's characterization. The reader can find information about the technique to determine residual stresses by XRD in specialized publications, such as Refs. [10-12]. One of the limitations of this conventional $\sin ^{2} \psi$ method arises when residual stress gradients are present in the irradiated surface layer or when it is necessary to characterize a very thin surface layer. Different approaches to solve this limitation have been made recently by different authors [13-16]. In this paper, the pseudograzing incidence method (PGIXRD; [17]) will be applied and will be summarized in the next paragraphs.

If we consider the experimental setup to determine residual stress by XRD in $\Psi$-mode, this setup is always symmetrically relative to the sample's surface; that is, the detector always moves at angle $2 \theta$ while the sample moves

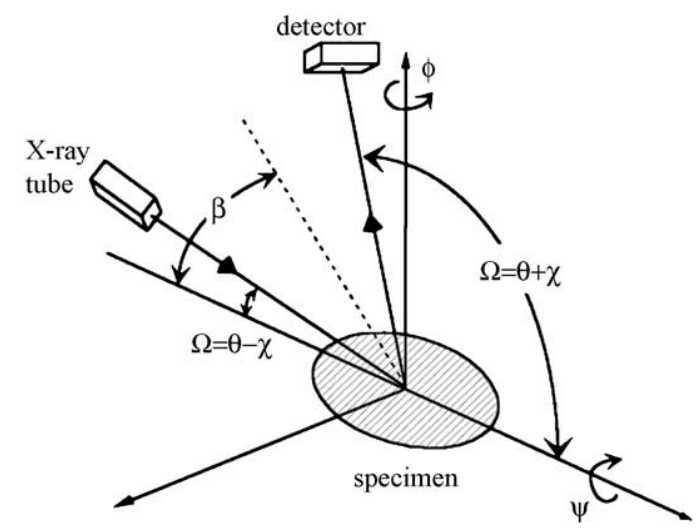

Fig. 2. Scheme of pseudograzing incidence geometry.
Table 1

Implantation conditions of samples

\begin{tabular}{llllll}
\hline $\begin{array}{l}\text { Sample } \\
\text { No. }\end{array}$ & Ion & $\begin{array}{l}\text { Total fluence } \\
\left(F, \times 10^{15} \mathrm{~cm}^{-2}\right)\end{array}$ & $\begin{array}{l}\text { Sample } \\
\text { No. }\end{array}$ & Ion & $\begin{array}{l}\text { Total fluence } \\
\left(F, \times 10^{15} \mathrm{~cm}^{-2}\right)\end{array}$ \\
\hline 1 & $\mathrm{Ar}$ & 0.39 & 5 & $\mathrm{~N}$ & 0.39 \\
2 & $\mathrm{Ar}$ & 0.65 & 6 & $\mathrm{~N}$ & 0.65 \\
3 & $\mathrm{Ar}$ & 1.95 & 7 & $\mathrm{~N}$ & 1.95 \\
4 & $\mathrm{Ar}$ & 3.90 & 8 & $\mathrm{~N}$ & 3.90 \\
\hline
\end{tabular}

at $\theta, \theta$ being the Bragg angle. For this geometry, the penetration depth, $\tau$ ( $\tau$ is the penetration depth of X-rays, which is defined by the condition that the intensity $I$ of the $\mathrm{X}$-rays passing through the material is $1 / e$ of the primary intensity $I_{0}$ ), can be calculated by the following equation [18,19]:

$\tau=\frac{\cos \psi \sin \theta}{2 \mu}$

where $\mu$ is the absorption coefficient of the irradiated material for the X-ray wavelength used.

A four-circle goniometer is required to implement the PGIXRD. A lower penetration depth of the radiation is achieved by reducing the incidence angle $\Omega$, defined as the angle between the incident beam and the sample surface. The penetration depth $\tau$, in this grazing incidence geometry, can be estimated by the equation $[18,19]$ :

$\tau=\frac{\cos \psi\left(\sin ^{2} \theta-\sin ^{2} \chi\right)}{2 \mu \sin \theta \cos \chi}$

where $\chi$ is the rotation of the sample, i.e., $\chi=\theta-\Omega$.

The idea underlying this method can be easily understood from Eq. (3) and Fig. 2. If the incidence angle is reduced, the penetration depth will also decrease, and by choosing different incidence angles, it will be possible to reach different surface layers of the material. The method however can only be applied if the residual stress gradient over the respective range of X-ray penetration depth is not steep; that is, the stress is assumed to be homogeneous in each of those layers. In the following, we will use a mean value, $z^{*}$, which was defined as the mean penetration depth at half/mid $\psi$ maximum value (for $-60^{\circ}<\psi<60^{\circ}$, $z^{*}=\tau_{\psi=30^{\circ}}$ ). The geometry proposed is presented in Fig. 2 . The $\Omega$ incidence angle must remain constant while the sample is rotated in a plane perpendicular to the plane defined by the incident and the diffracted X-ray beam in

Table 2

X-ray wavelengths $(\lambda K \alpha)$ for the different anticathodes used in the residual stress determinations by $\sin ^{2} \psi$ conventional method and corresponding mean penetration depth, $z^{*}$

\begin{tabular}{lllll}
\hline Anticathode & $\begin{array}{l}\text { Wavelength } \\
\mathrm{K} \alpha(\AA)\end{array}$ & $\{\mathrm{hkl}\}$ & $2 \theta\left(^{\circ}\right)$ & $\begin{array}{l}\text { Mean penetration } \\
\text { depth, } z^{*} \\
\left(\mathrm{~nm} ; z^{*}=\tau_{\left.\psi=30^{\circ}\right)}\right.\end{array}$ \\
\hline $\mathrm{Mn}$ & 2.1031 & $\mathrm{Fe}-\gamma\{311\}$ & 146.01 & 6520 \\
$\mathrm{Cr}$ & 2.2897 & $\mathrm{Fe}-\gamma\{220\}$ & 125.34 & 4700 \\
$\mathrm{Cu}$ & 1.5418 & $\mathrm{Fe}-\gamma\{420\}$ & 141.94 & 1720 \\
\hline
\end{tabular}


Table 3

Mean penetration depth of the $\mathrm{Cu} \mathrm{K} \alpha$ for $\mathrm{Fe}-\gamma\{420\}$ family planes for different angles of incidence $\Omega$

\begin{tabular}{llllll}
\hline Incidence angle $\Omega$ & $74^{\circ}(\Omega=\theta)$ & $45^{\circ}$ & $30^{\circ}$ & $20^{\circ}$ & $10^{\circ}$ \\
\hline $\begin{array}{c}\text { Mean penetration } \\
\text { depth, } z^{*}\end{array}$ & 1720 & 1470 & 1140 & 840 & 470 \\
$\left(\mathrm{~nm} ; z^{*}=\tau_{\psi=30^{\circ}}\right)$ & & & & & \\
\hline
\end{tabular}

order to determine the residual stress, as in the conventional $\Psi$-geometry. In other words, the sample must rotate in different $\psi$ inclinations. This new geometry is no longer a symmetric one, and $\Omega$ is no longer equal to the Bragg angle. It also means that for $\psi=0^{\circ}$, the diffracting planes are no longer parallel to the sample surface. Using different $\Omega$ incidence angles, the average penetration depth, $z^{*}$, can be changed, and the respective residual stresses are obtained as mean values over layers of different thickness.

The residual stress values are determined for this geometry following the procedure described in detail in reference [17].

\section{Experimental study}

The material used in the experiments was an austenitic AISI 304 stainless steel. Samples were cut from a same sheet (initially annealed) with rectangular shapes of $26 \times 16$ $\mathrm{mm}$, all in the same direction. The long dimension of the sample was used as the rolling direction $\left(\phi=0^{\circ}\right)$. The sample surfaces were mechanically polished in the rolling direction.

Eight samples were ion implanted under similar geometrical configuration, with a single ion beam pulse fluence $f=1.3 \times 10^{14}$ ions $\mathrm{cm}^{-2}$. Half of the samples were implanted with argon, and the other half with nitrogen ions, with four different total accumulated fluences. To compare the characteristics of the material before and after the implantation, half of each sample surfaces were covered by a thin titanium foil during the implantation process, leaving the other half exposed to the ion's beam. The details of the implantation conditions are presented in Table 1. The implantations were done with short pulse $(\delta t=400 \mathrm{~ns})$ at a CDP distance of $80 \mathrm{~mm}$, with a lapse between successive beam pulses of $\sim 20 \mathrm{~s}$, a time long enough to ensure the complete thermal relaxation of the sample after being heated

Table 4

XRD experimental conditions used to determine residual stresses depth profiles in AISI 304 surfaces with $\mathrm{Cu} \mathrm{K} \alpha$ radiation

\begin{tabular}{|c|c|c|c|c|}
\hline Radiation & $\{\mathrm{hkl}\}$ & $2 \theta_{0}\left(^{\circ}\right)$ & $\Omega\left({ }^{\circ}\right)$ & $\begin{array}{l}\text { Time per } \\
\text { step (s) }\end{array}$ \\
\hline \multirow[t]{5}{*}{$\mathrm{Cu} \mathrm{K} \alpha$} & $\mathrm{Fe}-\gamma\{420\}$ & 148 & $74(\Omega=\theta)$ & 15 \\
\hline & & & 45 & 15 \\
\hline & & & 30 & 15 \\
\hline & & & 20 & 25 \\
\hline & & & 10 & 25 \\
\hline
\end{tabular}

Table 5

X-ray elastic constants used for calculations of residual stresses in AISI 304 surfaces

\begin{tabular}{lll}
\hline & $1 / 2 \mathrm{~S}_{2}\left(10^{-6} \mathrm{MPa}^{-1}\right)$ & $\mathrm{S}_{1}\left(10^{-6} \mathrm{MPa}^{-1}\right)$ \\
\hline $\mathrm{Fe}-\gamma\{311\}$ & 6.98 & -1.87 \\
$\mathrm{Fe}-\gamma\{220\}$ & 6.05 & -1.56 \\
$\mathrm{Fe}-\gamma\{420\}$ & 6.95 & -1.92 \\
\hline
\end{tabular}

by the preceding beam, ensuring that the following one will reach the surface when it returns to room temperature. Besides, the gap between successive pulses enables to charge and discharge the axial capacitor.

The XRD study was performed both in the implanted zone and in the nonimplanted zone in order to understand the effect of the ion implantation. The analysis was made in the rolling and transverse directions $\left(\phi=0^{\circ}\right.$ and $\phi=90^{\circ}$, respectively). The same process was applied to all samples implanted with different fluence for both ions ( $\mathrm{N}$ and $\mathrm{Ar}$ ).

The phase analysis was done in all samples by XRD with $\mathrm{Cr} \mathrm{K} \alpha$ radiation.

Four poles figures Fe- $\alpha^{\prime}\{110\}, \mathrm{Fe}-\gamma\{111\}, \mathrm{Fe}-\gamma\{200\}$, and $\mathrm{Fe}-\gamma\{220\}$ were acquired with $\mathrm{Cr} \mathrm{K} \alpha$ radiation in the implanted and nonimplanted surfaces to determine the effect

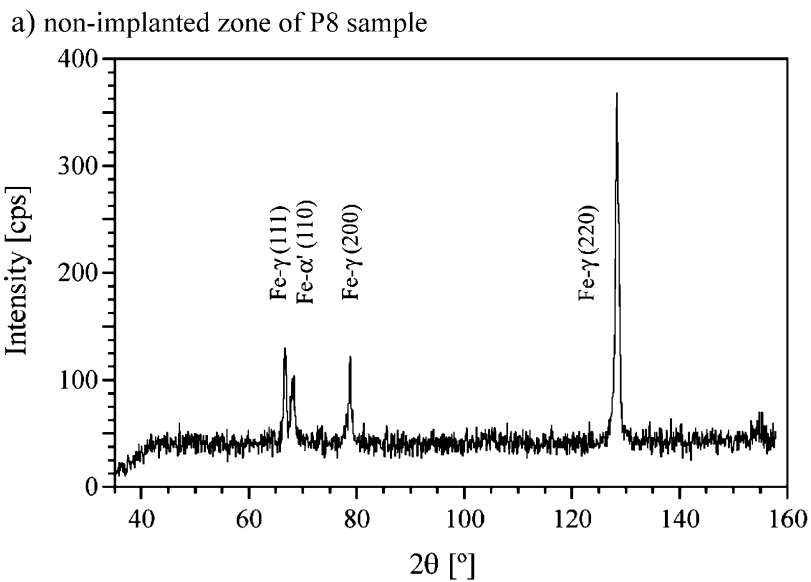

b) implanted zone of P8 sample (higher nitrogen fluence)

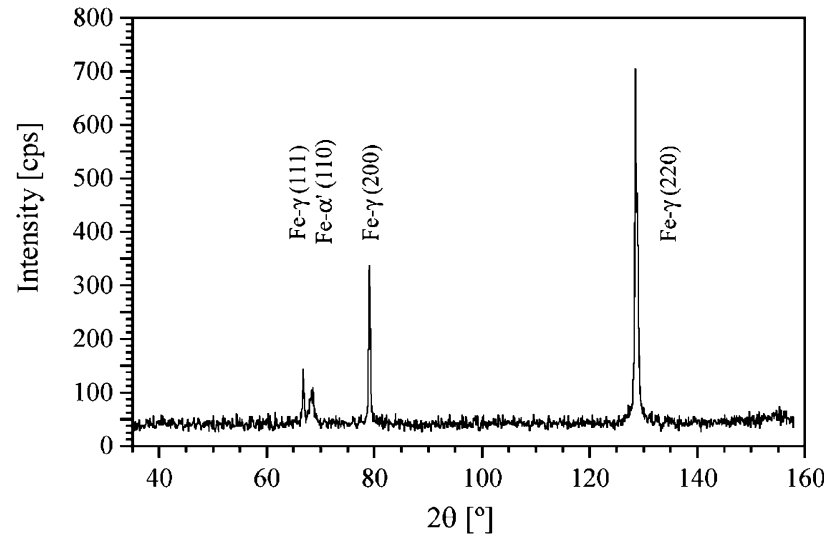

Fig. 3. Phase identification before and after the ion implantation process. (a) non-implanted zone of P8 sample; (b) implated zone of P8 sample (higher nitrogen fluence). 
of ion implantation in the crystallographic textures in all treated surfaces.

The determination of residual stress state at different depths was done first by the conventional $\sin ^{2} \psi$ method, using $\mathrm{Mn}, \mathrm{Cr}$, and $\mathrm{Cu} \mathrm{K} \alpha$ radiations. The use of the $\sin ^{2} \psi$ conventional method with several wavelength enables to achieve the mean penetration depth $z^{*}$ presented in Table 2. $z^{*}$ was calculated, by the Eq. (3) defined in previous section (Section 1.2), for each angle selected in function of each wavelength and considering $\psi=30^{\circ}$. This XRD method is used very often to determine residual stresses in depth because it is a nondestructive method, but it has the disadvantage of X-ray tube changing between each acquisition.

The lower penetration depth attainable by the conventional method is obtained with $\mathrm{Cu} \mathrm{K} \alpha$ radiation $\left(z^{*}=1720\right.$ $\mathrm{nm}$ ) as it can be seen in Table 2. To reach a shallow depth, the PGIXRD method with $\mathrm{Cu} \mathrm{K} \alpha$ radiation was used with the experimental incidence angles $\Omega$ listed in Table 3 .

In Table 4, the XRD experimental conditions used to characterize the residual stress profiles of AISI 304 samples using conventional and pseudograzing methods with $\mathrm{Cu} \mathrm{K} \alpha$ radiation are listed. A CCD Germanium detector, which has a very high energy resolution, was used to collect the diffracted radiation. To minimize defocusing problems, a Soller slit with 0.4 rad divergence was used in front of the detector. A collimator with a 2-mm circular aperture was used in the incident X-ray beam. The residual stresses have been determined by peak shift of Fe- $\gamma$ for $11 \psi$ angles, between $+60^{\circ}$ and $-60^{\circ}$, using a step size equal to $0.1^{\circ}$. In Table 5, the X-ray elastic constants, used to determine the residual stresses in AISI 304 surfaces for each $\{\mathrm{hkl}\}$ plane used, are listed. These constants were calculated from single-crystal compliances assuming the Self-Consistent model. a) $\mathrm{Fe}-\alpha^{\prime}(110)$

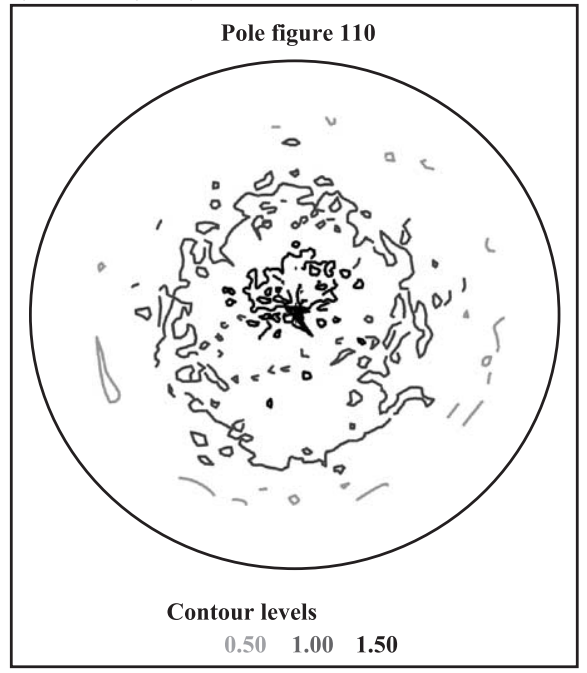

c) $\mathrm{Fe}-\gamma(200)$

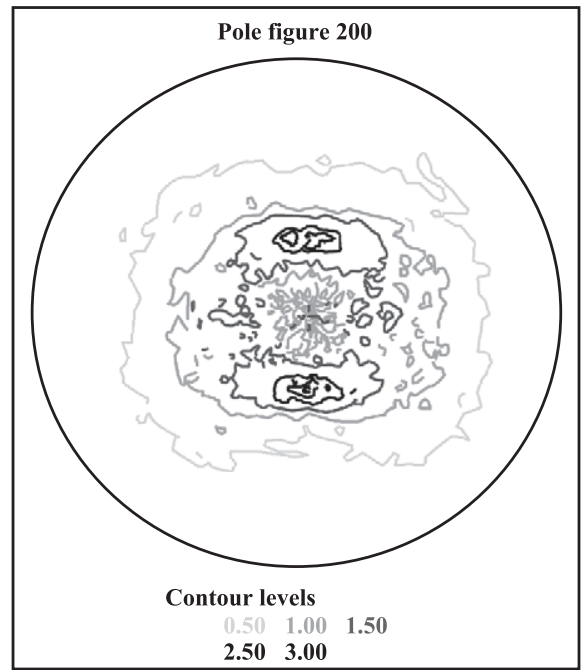

b) $\mathrm{Fe}-\gamma(111)$

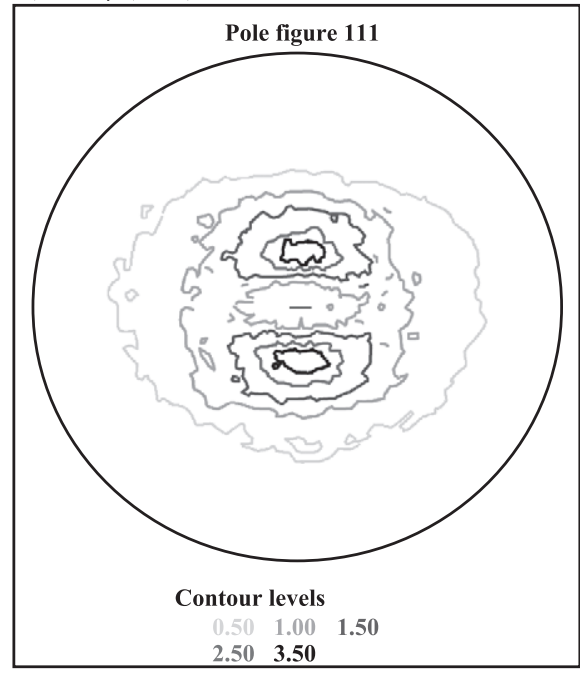

d) $\mathrm{Fe}-\gamma(220)$

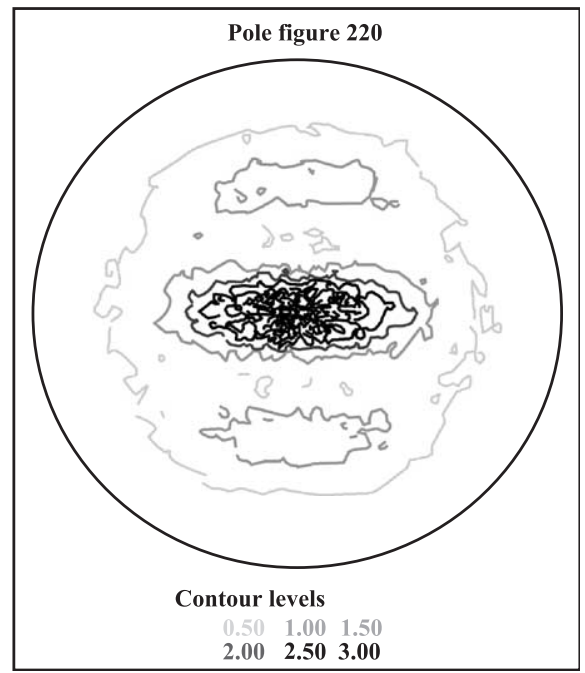

Fig. 4. Pole figures obtained in nonimplanted zone of P4 sample. (a) Fe- $\alpha^{\prime}\{110\}$, (b) Fe- $\gamma\{111\}$, (c) Fe- $\gamma\{200\}$, and (d) Fe- $\gamma\{220\}$. 


\section{Experimental results and discussion}

The phase analysis made by XRD does not show any significant change after the ion implantation treatment, as it can be seen in Fig. 3. The austenitic phase is the major phase, and the presence of some cold-worked martensite is also identified. The origin of cold-worked martensite could be explained by the mechanical polishing made in all samples before the ion implantation process. The diffraction patterns for all samples are similar to those presented in Fig. 3.

Despite this study, no evidence of any phase transformation after ion implantation, the presence of $\mathrm{Fe}_{2} \mathrm{~N}$ at $3600 \mathrm{~nm}$ deep has been previously detected by X-ray spectroscopy and by XRD [6]. However, that study refers to an ion implantation process which had been made with a higher beam fluence $\left(f=1.3 \times 10^{17}\right.$ ions $\left./ \mathrm{cm}^{2}\right)$. If $\mathrm{Fe}_{2} \mathrm{~N}$ is eventually present in our samples, the quantity formed was not sufficient to be identified by XRD.

a) $\mathrm{Fe}-\alpha^{\prime}(110)$

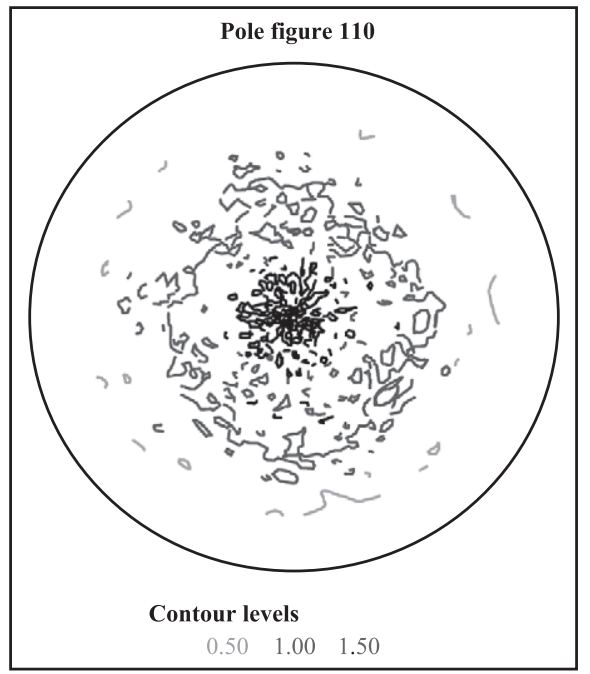

c) Fe- $\gamma(200)$

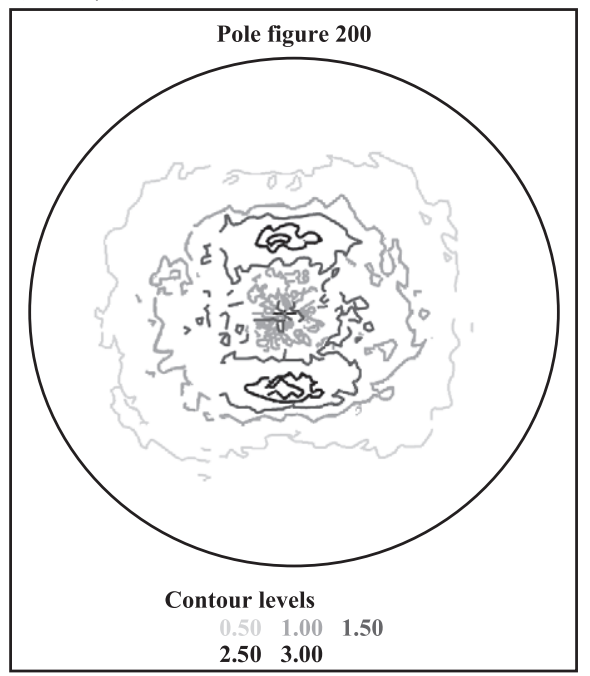

In Figs. 4 and 5, the pole figures determined in nonimplanted and in implanted zones of the P4 sample surface can be seen. The pole figures obtained for all other samples are similar to these figures. Observing the figures, it can be concluded that the ion implantation process does not affect the crystallographic texture; that is, after the ion implantation, the texture observed is similar to the texture registered in nonimplanted zones. The pole figures present a typical rolling texture. In spite of the presence of the texture, it has been possible to determine the residual stresses by the usual $\sin ^{2} \psi$ method, because the curve $\varepsilon$ vs. $\sin ^{2} \psi$ did not present "snake distribution".

The residual stress depth profiles, obtained in the rolling and transversal direction in the nonimplanted zones and in the implanted zones with argon ions, can be seen in Figs. 6 and 7. Figs. 8 and 9 show the profiles determined in the samples, which had been subjected to nitrogen ion implantation. From the observation of these figures, it can be observed that the profiles obtained in the nonimplanted

b) Fe- $\gamma(111)$

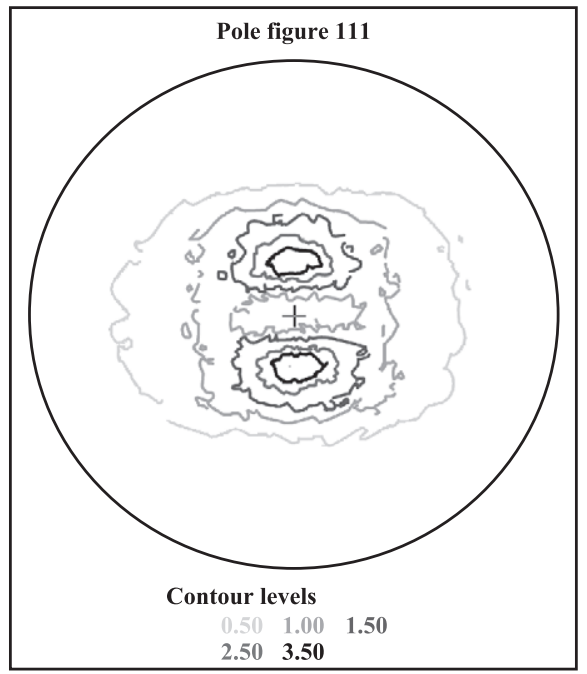

d) Fe- $\gamma(220)$

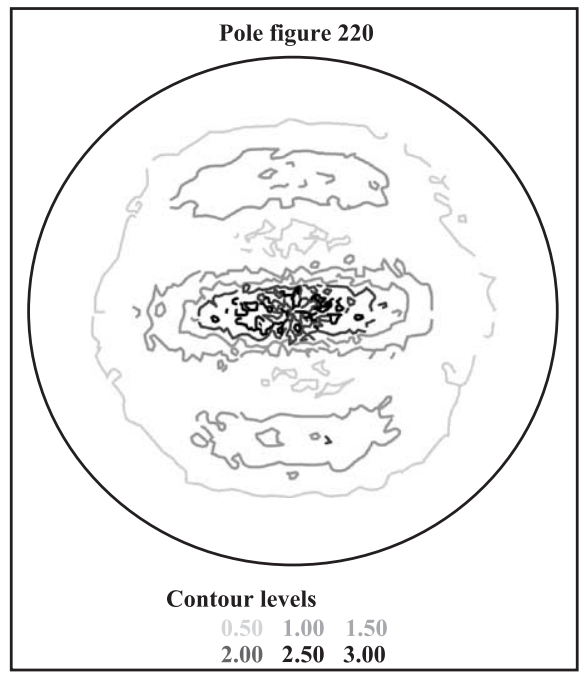

Fig. 5. Pole figures obtained in argon implanted zone of P4 sample. (a) Fe- $\alpha^{\prime}\{110\}$, (b) Fe- $\gamma\{111\}$, (c) Fe- $\gamma\{200\}$, and (d) Fe- $\gamma\{220\}$. 
a) non-implanted zone

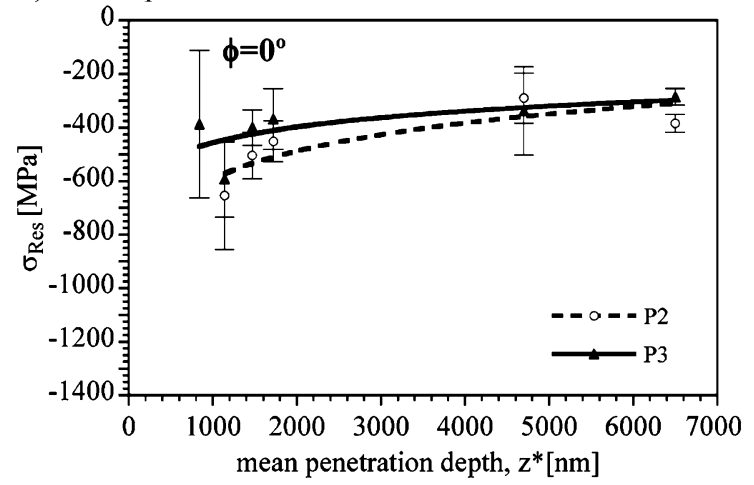

b) argon implanted zone

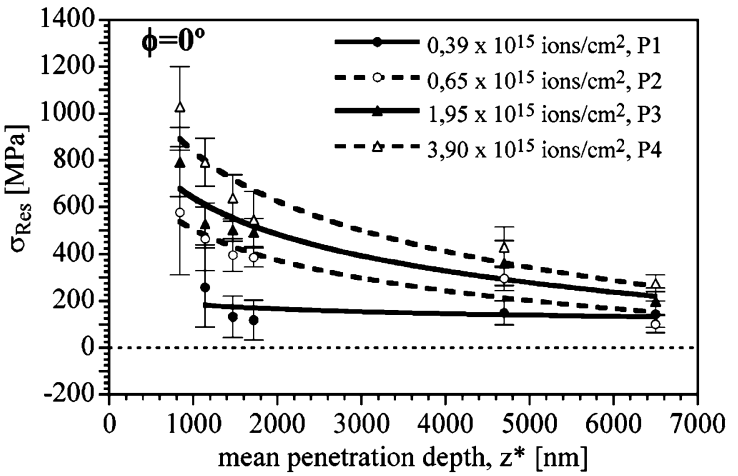

Fig. 6. Depth residual stresses profiles in AISI 304 surface in $\phi=0^{\circ}$ direction. (a) Nonimplanted zone and (b) argon-implanted zone.

a) non-implanted zone

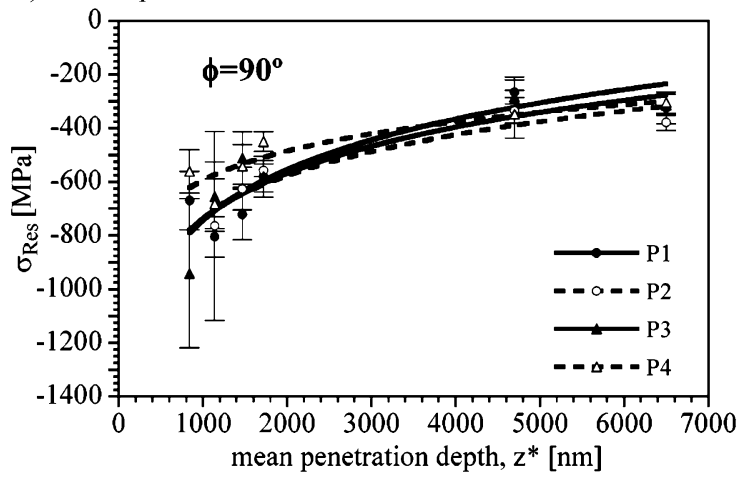

b) argon implanted zone

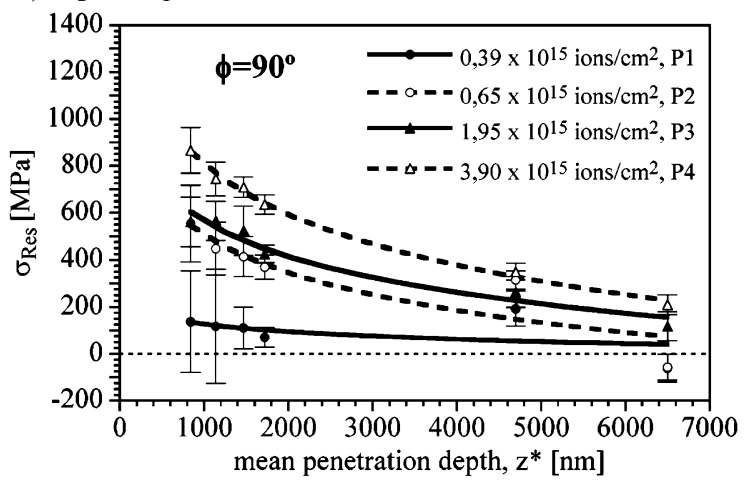

Fig. 7. Depth residual stresses profiles in AISI 304 surface in $\phi=90^{\circ}$ direction. (a) Nonimplanted zone and (b) argon-implanted zone. a) non-implanted zone

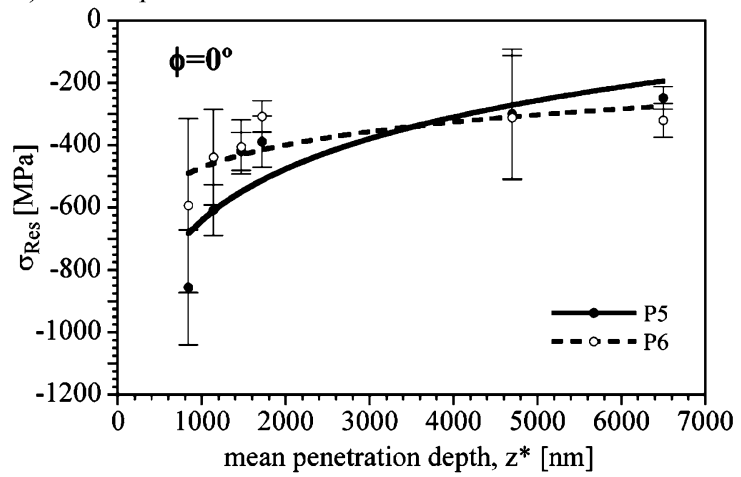

b) nitrogen implanted zone

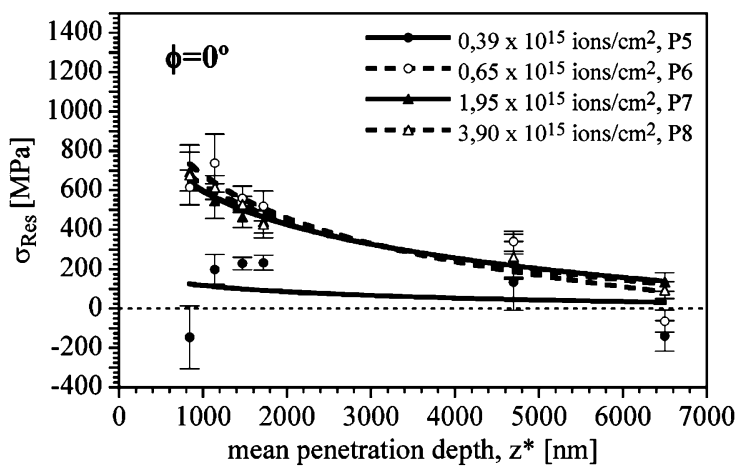

Fig. 8. Depth residual stresses profiles in AISI 304 surface in $\phi=0$ direction. (a) Nonimplanted zone and (b) nitrogen-implanted zone.

a) non-implanted zone

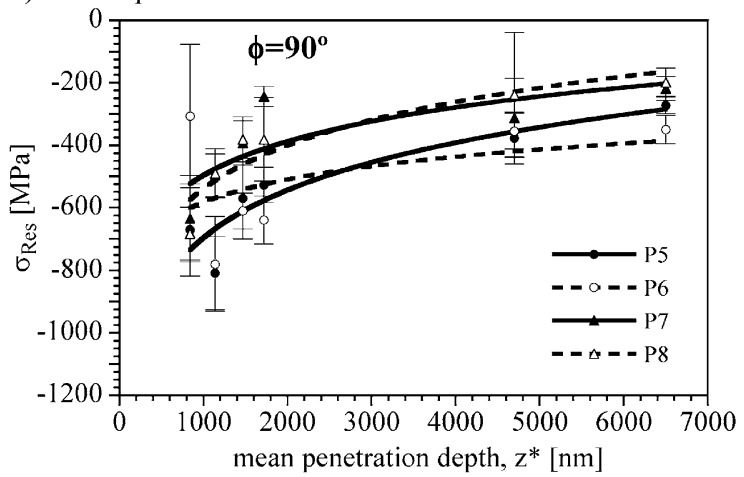

b) nitrogen-implanted zone

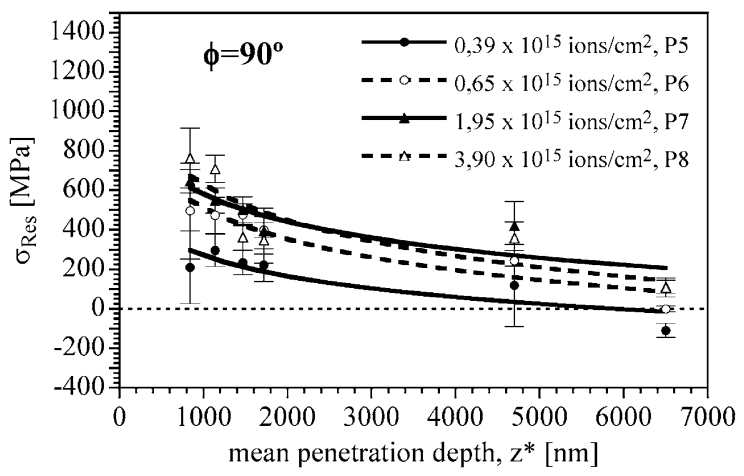

Fig. 9. Depth residual stresses profiles in AISI 304 surface in $\phi=90^{\circ}$ direction. (a) Nonimplanted zone and (b) nitrogen-implanted zone. 
zones are very similar (compressive profiles), which guarantee that the ion implantation has been made in similar samples. It can also be observed in Figs. 6 and 7 or in Figs. 8 and 9 that the profiles obtained in both directions do not present any significant change. As it can be seen, the initial compression residual stress profile, observed in the nonimplanted surfaces samples, changes to a tensile residual stress profile after implantation. A very important residual stress gradient is induced during ion implantation in a 6000to $7000-\mathrm{nm}$ thickness surface layer. These tensile residual stress values are higher in the first $2000 \mathrm{~nm}$ of the surface and then decrease to weaker values between -100 and 300 $\mathrm{MPa}$ at $6000-$ to $7000-\mathrm{nm}$ depth. It should also be noted that the gradient is sensitive to the dose of ions implanted, because increasing the beam fluence, the tensile residual stresses observed are higher; that is, the gradient becomes more significant with the increase of the ions' beam fluence. Comparing the effect of each type of ions, it can be concluded that the argon implantation induces higher residual stress values than nitrogen implantation. As an example, consider the ion implantation made with higher fluence $\left(f=3.4 \times 10^{-15}\right.$ ions $\left./ \mathrm{cm}^{2}\right)$ : in the case of argon implantation, the maximum residual stresses is in the order of $+1000 \mathrm{MPa}$, observed in $1000 \mathrm{~nm}$ bellow the surface (Fig. 6b), while the residual stress observed in the case of nitrogen implantation, at same depth, does not exceed +800 MPa (Fig. 8b).

The diffraction peak width evolution in depth is also similar in nonimplanted and in implanted zones, which can be observed in Fig. 10 in the case of argon implantation. Relatively to nitrogen implantation, the peak broadening presents a similar evolution. It should be noticed that the peak is much larger in the first micron of the surface layer, decreasing at a greater depth, reaching the corresponding peak value of recrystallized material $(6000-7000 \mathrm{~nm})$.

In order to understand the evolution of the results presented in this paper, the following must be taken into consideration. As it was already referred in Section 1.1, the ions are accelerated in the plasma torch with an energy distribution that follows Eq. (1). For the beam used in this work, the energy distribution law enables one to predict a high number of ions with lower energies. For practical reasons, and as a first approximation, we could consider that the number of ions with an energy $E<300 \mathrm{keV}$ can be disregard, because the relation $N(E=300 \mathrm{keV}) / N(E=20 \mathrm{keV})$ is equal to $1.5 \times 10^{-3}$. On the other side, taking into account the order of the penetration depth of nitrogen and argon in steels, calculated for a beam fluence with an energy of 300 $\mathrm{keV}$ which is $\approx 290$ and $\approx 140 \mathrm{~nm}$, respectively [20], it should be also expected, as a first approximation, that the superficial layer affected by ion implantation should be in the same order of magnitude. In a publication [6], the atomic concentration distribution profile in the surface layer of AISI 304 samples after nitrogen implantation, with a fluence of $1.3 \times 10^{17} \mathrm{ions} / \mathrm{cm}^{2}$ made with the same plasma torch used in this work, is indicated. The results presented in that a) non-implanted zone

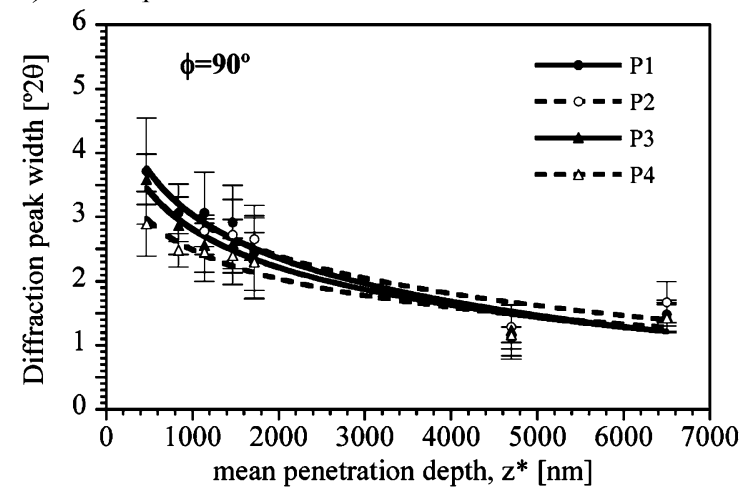

b) argon implanted zone

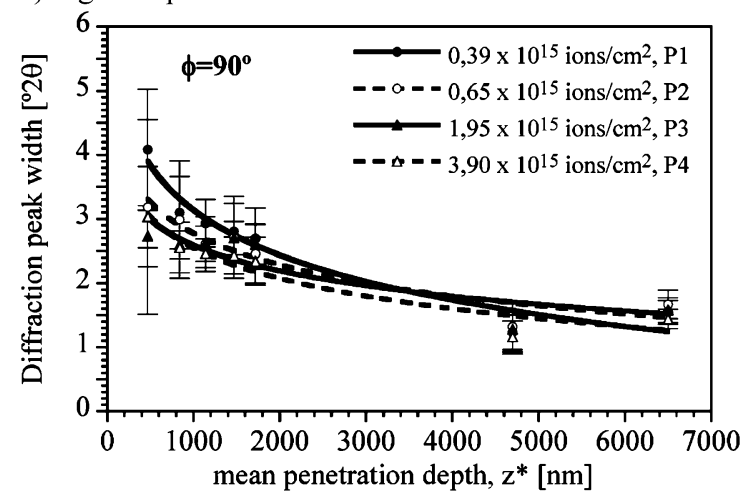

Fig. 10. In-depth diffraction peak width evolution in AISI 304 surfaces. (a) non-implanted zone; (b) argon implanted zone.

publication show a slow decrease in nitrogen concentration with depth after the first $30 \mathrm{~nm}$, attaining a maximum of 12 at. $\%$ in that layer. The concentration profile after that first 30 $\mathrm{nm}$ presents a smooth change from 8 at. $\%$ at $30 \mathrm{~nm}$ to 4 at. $\%$ at $360 \mathrm{~nm}$ (the deeper layer observed by X-ray spectroscopy). Due to the uniformity of this profile or to the penetration depth reached, the concentration profile implies a flux of ions in the sample with energies until $500 \mathrm{keV}$. This being the case, it can be observed that the penetration depth reached by nitrogen-implanted ions is greater than the calculated depth penetration $(290 \mathrm{~nm})$, considering hypothesis from a strict ion energetic point. The reason for this unexpected depth profile concentrations can be related to the fact that the ion beam is being pulsed in several periods of short duration, inducing a quickly and strong thermal effect in the surface due to the energy released, which are responsible for the uniform nitrogen profiles observed. This hypothesis is corroborated with a study of numeric simulation $[21,22]$, in which are estimated surface temperatures, during the implantation, close to the melting point of steels.

Because the argon ions induce a higher gradient of residual stresses than the nitrogen ions, and taking into account the different order of penetration of each ion, clearly, it can be concluded that the residual stresses profiles determined in this paper could not be related with this parameter. The tensile nature of the residual stress can be 
justified by the compressive plastic strain of the constricted surface layer during fast heating, which turns into tensile residual stress state after cooling. This thermal effect will be produced simultaneously with the ion implantation process in each pulse and will be repeated $n$ times during the repetitive process of pulsed ion implantation. This effect is similar to other results about ion implantation already published [23]. Complementary studies will be necessary to propose a thermomechanical model that is able to take into account the energy of the ions.

\section{Conclusion}

In this work, the influence of argon and nitrogen implantation in austenitic AISI 304 stainless steel was determined. The study concerned phase analysis, crystallographic texture, and depth residual stresses profile characterization by XRD. The residual stresses profiles were obtained with $\mathrm{Mn}, \mathrm{Cr}$, and $\mathrm{Cu} \mathrm{X}$-ray radiation that enables a $6520-$, 4700-, and 1720-nm depth surface layers analysis, respectively. In order to achieve an even lower X-ray penetration, the method called pseudograzing incidence X-ray diffraction (PGIXRD) was used to determine residual stresses until $470 \mathrm{~nm}$.

From experimental data, the following conclusions may be drawn:

- no phase changes were observed after the ion implantation for both types of ions implanted;

- no crystallographic texture changes were observed after the ion implantation for both types of ions. The texture observed in nonimplanted zones and in implanted zones is similar, and it can be related to the rolling process made in all samples before implantation;

- an important tensile stress gradient is induced in ionimplanted surfaces;

- the increase of ion beam fluence increases the tensile residual stress level. The residual stresses profile seems to be strongly dependent of the thermal shock magnitude occurring in the sample surface;

- Ar ions have shown to have a more important effect than $\mathrm{N}$ ions in the magnitude of the stress gradient induced during implantation;

- the X-ray diffraction peaks' widths are not strongly affected by the ion implantation treatment for both types of ions.

\section{Acknowledgments}

The X-ray experiments were performed in the frame of the POCTI/33681/CTM 2000 Project, which was approved by the National Foundation for the Science and Technology (FCT, Portugal) and the POCTI programme and was sponsored by the European Found FEDER. This work was also partially supported by IAEA (Research Contract No. RC/6477/R1/RB) and CONICET grants (Argentine).

\section{References}

[1] I. Kanno, K. Nomoto, S. Nishijima, et al., Nucl. Instrum. Methods Phys. Res. 59/60 (1991) 920.

[2] R. Günzel, E. Wieser, E. Richter, J. Steffen, J. Vac. Sci. Technol. B 12/ 2 (1994) 927

[3] K.C. Walter, J. Vac. Sci. Technol. B 12/2 (1994) 945.

[4] A.M. Becdelièvre, J.D. Becdelièvre, A. Desestret, et al., Mater. Tech. (1989) 13, Janvier-Février.

[5] J.W. Mather, Plasma Phys. Control. Nucl. Res. 2 (1965) C21/80

[6] J. Feugeas, E. Llonch, C.O.D. Gonzalez, G. Galambos, J. Appl. Phys. 64/5 (1988) 2648.

[7] M.J. Rhee, Appl. Phys. Lett. 37 (1980) 906.

[8] W. Stygar, G. Gerdin, F. Venneri, J. Mandrekas, Nuc. Fus. 22 (1982) 1161.

[9] E. Macherauch, P. Müller, Z. Angew. Phys. 13 (1961) 305.

[10] V. Hauk, Structural and Residual Stress Analysis by Nondestructive Methods. Evaluation-Application-Assessment, 1st edition, Elsevier B. V., Amsterdam, 1997.

[11] M. François, J.M. Sprauel, C.F. Déhan, M.R. James, F. Convert, J. Lu, J.L. Lebrun, N. Ji, R.W. Hendricks, in: J. Lu (Ed.), X-Ray Diffraction Method, Handbook of Measurement of Residual Stresses, Society for Experimental Mechanics, The Fairmont Press, Lilburn, 1996, p. 71.

[12] C.I. Noyan, J.B. Cohen, Springer-Verlag, New York, 1987.

[13] P. Predecki, X. Zhu, B. Ballard, Adv. X-Ray Anal. 36 (1993) 237.

[14] H. Ruppersberg, Adv. X-Ray Anal. 37 (1994) 235.

[15] B. Eigenmann, E. Macherauch, Nucl. Instrum. Methods Phys. Res. B Beam Interact. Mater. Atoms 97 (1995) 92.

[16] C. Genzel, Phys. Status Solidi, A, Appl. Res. 156 (1996) 353.

[17] M.J. Marques, A.M. Dias, P. Gergaud, J.L. Lebrun, Mater. Sci. Eng. A, Struct. Mater:: Prop. Microstruct. Process. 287 (2000) 78.

[18] T. Dümmer, B. Eigenmann, D. Löhe, in: M.H. Aliabadi, C.A. Brebbia (Eds.), Proc. Third International Conference on Computer Methods and Experimental Measurements for Surface Treatment Effects; Surface Treatment, Oxford, UK, July 15-17 1997, Computational Mechanics Publications, Southampton, 1997, p. 371.

[19] A. Schubert, B. Kämpfe, E. Auerswald, B. Michel, in: V. Hauk, H.P. Hougardy, E. Macherauch, H.-D. Tietz (Eds.), Residual Stresses, DGM Informationsgesellschaft, Verlag, Oberursel, 1992, p. 663 .

[20] J.F. Zigler, J.P. Biersack, U. Littmark, The Stopping and Range of Ions in Solids, Pergamon, New York, 1985.

[21] S.P. Brühl, G. Sanchez, M. Storti, A. Cardona, J.N. Feugeas, G. Kaufmann, J. Phys., D, Appl. Phys. 28 (1995) 1655.

[22] G. Sanchez, J.N. Feugeas, J. Phys., D, Appl. Phys. 30 (1997) 927.

[23] A.A. Pochettino, J. Feugeas, M. Ortiz, G. Sanchez, in: H. Fujiwara, T. Abe, E.K. Tanaka (Eds.), Residual Stresses in Ion Implanted Steels, Proc. Residual Stresses-III: Science and Technology (ICRS3), Tokushima, Japan, 23-26 July 1991, vol. 2, Elsevier Publishers Lda, England, 1992, p. 833. 